\title{
Activity-Dependent Potentiation of Recurrent Inhibition: A Mechanism for Dynamic Gain Control in the Siphon Withdrawal Reflex of Aplysia
}

\author{
Thomas M. Fischer, ${ }^{1}$ and Thomas J. Carew ${ }^{1,2}$ \\ Departments of ${ }^{1}$ Psychology and ${ }^{2}$ Biology, Yale University, New Haven, Connecticut 06520
}

\begin{abstract}
The siphon withdrawal response (SWR) of Aplysia supports several forms of learning that are under both excitatory and inhibitory control. Here we examine the role of interneuronal processing on the regulation of siphon responses, with an emphasis on the role of inhibition. We focus on the recurrent circuit formed by the excitatory interneuron L29 and the inhibitory interneuron L30, and show that this circuit provides a mechanism for use-dependent regulation of excitatory input onto siphon motor neurons.
\end{abstract}

We utilized a reduced preparation in which input to the SWR circuit was elicited by taps applied to the siphon; tapevoked EPSPs were measured in LFS siphon motor neurons. We first show that L29 is an important source of excitatory input to LFS motor neurons: voltage-clamp inactivation of a single L29 (out of five) results in a significant reduction of tap-evoked EPSPs. Next, we demonstrate that direct intracellular activation of L29, surprisingly, produces transient inhibition of evoked input to motor neurons that lasts up to 40 sec. We then provide several lines of evidence that the mechanism of L29-induced inhibition is through the recruitment and potentiation of recurrent inhibition from L30: (1) L29 activation results in reduced tap-evoked responses of other (nonactivated) L29s; (2) direct activation of L 30 mimics the inhibitory effects produced by L29 activation (LFS neurons receive no direct synaptic input from $L 30$ ); and (3) the L30 IPSP is significantly potentiated as a result of its own activity, whether produced directly (by L30 activation) or indirectly (through L29 activation). This IPSP potentiation has the same time course as L29-induced inhibition of motor neuron responses. Thus activity-dependent potentiation of L30 transmission can inhibit motor neuron responses, in part through inactivation of the L29 interneuronal pool. Finally, we propose that L29-L30 interactions provide a mechanism for dynamic gain control in the SWR.

[Key words: interneuron, neuronal network, synaptic plasticity, abdominal ganglion, motor neuron, learning]

A fundamental goal in neuroscience is to elucidate the general principles of neural network operation that are involved in the generation of behavior. Of particular interest are processes that

\footnotetext{
Received June 19, 1992; revised Sept. 21, 1992; accepted Oct. 1, 1992.

We thank D. Blazis, N. Emptage, K. Fitzgerald, and E. Marcus for valuable comments on an earlier version of the manuscript. This work was supported by NHS Grants T32-NS07102-14 and T32-MH1839705 to T.M.F., and by NSF Grant BNS8311300, NIH Grant R01-MH-14-1083, and AFOSR Award AF 890362 to T.J.C.

Correspondence should be addressed to Thomas J. Carew, Yale University Department of Psychology, P.O. Box 11 A Yale Station, New Haven, CT 065207447.

Copyright (C) 1993 Society for Neuroscience $0270-6474 / 93 / 131302-13 \$ 05.00 / 0$
}

underlie adaptive modifications in the output of a network that result from experience, such as learning. A recurrent theme that has emerged from work in a diverse variety of systems is that changes in behavior produced by learning involve multiple, activity-dependent alterations in synaptic efficacy that are distributed throughout a neural network (for review, see Kesner, 1984; Getting, 1989; Thompson, 1989; Weinberger et al., 1990; Harris-Warrick and Marder, 1991; Levine and Leven, 1991). This inherent network capability for distributed plasticity raises a fundamental challenge in relating alterations in synaptic transmission or intrinsic cellular properties observed at the singlecell level to the modification of the functional output of a neural network.

The siphon withdrawal response (SWR) of the marine mollusk Aplysia californica is useful for addressing these questions, since in this preparation it is possible to relate quantifiable modifications in behavior directly to cellular plasticity within a defined neural circuit (Kandel, 1979; Carew and Sahley, 1986). Numerous studies have shown that the SWR supports both associative and nonassociative learning, which exist in short- and long-term forms (for review, see Carew and Sahley, 1986; Byrne, 1987; Hawkins et al., 1987). Moreover, the SWR undergoes both facilitatory and inhibitory modulation in a stimulus-dependant fashion (Mackey et al., 1987; Marcus et al., 1988; Wright et al., 1991; for review, see Fitzgerald et al., 1990). The cellular basis of SWR plasticity has been extensively investigated. Many studies have focused on the modification of the monosynaptic EPSP between siphon sensory neurons (LE type) and siphon motor neurons (Castellucci and Kandel, 1976; Kandel and Schwartz, 1982; Hawkins et al., 1983; Walters, 1989; Small et al., 1992). Recent observations suggest that other sites and mechanisms also play an important role in plasticity. For example, tail shock-induced inhibition of the SWR is paralleled by a significant inhibition of the net, complex synaptic input onto motor neurons evoked by siphon stimulation, while at the same time the monosynaptic EPSP from LE sensory neurons to these same motor neurons is facilitated (Wright et al., 1991). A similar result, facilitation of the sensory neuron monosynaptic EPSP but inhibition of both the SWR and the complex EPSP, was found in response to exogenous application of 5-HT (Fitzgerald and Carew, 1991), a neurotransmitter implicated in facilitation of the SWR (Brunelli et al., 1976; Abrams et al., 1984). These opposite effects on sensory neuron monosynaptic transmission and the polysynaptic input to siphon motor neurons show that other synaptic connections, presumably involving interneurons in the siphon withdrawal circuit, play an important role in the modulation of the SWR (Fitzgerald et al., 1990; Fitzgerald and Carew, 1991; Wright et al., 1991; see also Frost et al., 1988). 
A
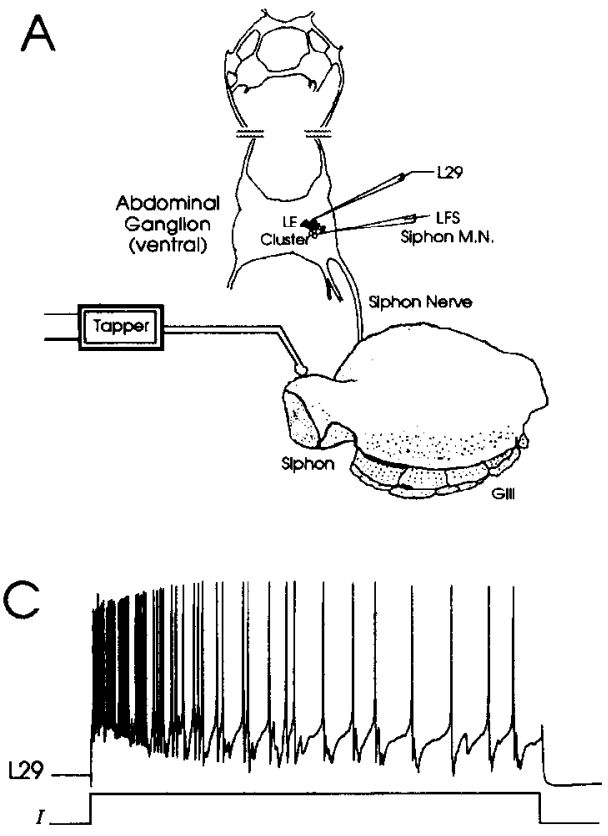

B

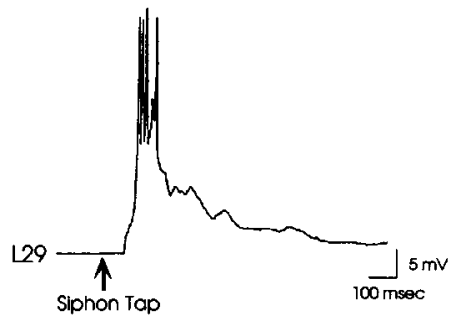

D

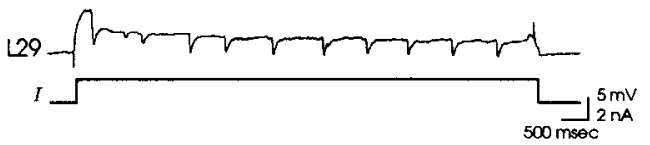

Figure 1. Schematic drawing of reduced preparation, and physiological criteria used to identify interneuron L29. $A$, Reduced preparation (see Materials and Methods). B, Response in L29 evoked by a brief $(60 \mathrm{msec})$ tap to the siphon. I.29 interneurons typically fire a burst of two to eight action potentials per siphon tap. $C$, Injection of depolarizing current $(I)$ into $\mathrm{L} 29$ recruits a series of IPSPs, producing a typical "stuttering" pattern in L29. D, Injection of depolarizing current into L29 that is below threshold for producing action potentials can also recruit recurrent IPSPs.
In this article, we begin to investigate the role of interneuronal processing in the modification of siphon responses by focusing on a class of identified excitatory interneurons in the abdominal ganglion, the L29 cells. First described by Hawkins et al. (1981a), these neurons are particularly attractive to study since, in addition to providing direct excitatory input to siphon motor neurons, they have the ability to act as neuromodulators in the SWR circuit (Frost et al., 1988; Hawkins et al., 1981a,b). For example, direct intracellular activation of $\mathrm{L} 29$ has been shown to facilitate LE sensory neuron monosynaptic transmission both in vivo (Hawkins et al., 1981b) and in vitro (Hawkins and Schacher, 1989). We present evidence here that L29 itself can be an important site for modifications of siphon responses through the regulation of its direct excitatory input to siphon motor neurons. First, we demonstrate that L29 provides a significant proportion of stimulus-evoked input to a particular class of siphon motor neurons, the LFS cells. Next, we demonstrate the novel finding that direct intracellular activation of L29 produces significant inhibition of evoked input to LFS neurons. Finally, we provide evidence that the mechanism of L29-induced inhibition involves recruitment of an identified class of inhibitory interneurons, the $\mathrm{L} 30$ cells, which exhibit an activity-dependent potentiation of inhibitory synaptic transmission. Thus, L29's activity recruits and potentiates inhibition back onto itself, in effect transiently removing itself from the SWR circuit. In this fashion, L29-L30 interactions provide a mechanism for an activity-dependent regulation of excitatory input to siphon motor neurons, thus acting as a dynamic gain control circuit in the SWR network.

Some of the results in this article have been presented in abstract form (Fischer and Carew, 1991).

\section{Materials and Methods}

\section{Animals}

Adult Aplysia californica (100-300 gm) were obtained commercially (Marinus Inc., Long Beach, CA) and maintained in a 600 liter aquarium containing continuously circulating, aerated Instant Ocean (Aquarium Systems, Mentor, $\mathrm{OH}$ ) at $15^{\circ} \mathrm{C}$. Animals were housed in groups of up to six, and fed once weekly with dried seaweed.

\section{Reduced preparation}

An isolated siphon/gill preparation was used in our experiments (Fig. 1A). Animals were first anesthetized by injection of isotonic $\mathrm{MgCl},(50 \%$ of body weight) into the body cavity. The central nervous system (abdominal, pedal, pleural, and cerebral ganglia) and the mantle organs (siphon and gill) were then removed from the animal; all peripheral nerves except the siphon nerve were cut. The preparation was then transferred to a Sylgard (Dow-Corning)-coated recording dish containing $50 \% \mathrm{MgCl}_{2}, 50 \%$ artificial sea water (ASW; $460 \mathrm{mM} \mathrm{NaCl}, 55 \mathrm{~mm}$ $\mathrm{MgCl}_{2}, 11 \mathrm{~mm} \mathrm{CaCl}, 10 \mathrm{~mm} \mathrm{KCl}, 10 \mathrm{~mm}$ Tris, $\mathrm{pH}$ 7.4) and pinned with the mantle dorsal side up and the siphon unobstructed. The abdominal ganglion was pinned on a recording platform ventral side up, and the left hemiganglion surgically desheathed. The preparation was then continuously perfused with ASW (room temperature, $19-22^{\circ} \mathrm{C}$ ) throughout the experiment. At least $1 \mathrm{hr}$ of postdissection recovery time was allowed prior to physiological recordings, after which evoked contractions of the siphon and gill could readily be elicited by a tactile stimulus to the siphon.

\section{Electrophysiology}

Standard intracellular recording techniques were used. Neurons were impaled with glass microelectrodes (resistance, 5-10 M 2 ) containing either $3 \mathrm{M} \mathrm{KCl}$ or $3 \mathrm{M} \mathrm{K}$-acetate. Electrical potentials were amplified on Getting 5-A intracellular amplifiers (Getting Instruments, lowa City, IA), and then digitized (Medical Systems Corp., Greenvale, NY) for tape storage and computer analysis. Standard two-electrode voltageclamp experiments were performed using an Axoclamp 2-A voltageclamp amplifier (Axon Instruments, Burlington, $\mathrm{CA}$ ).

Input to the siphon withdrawal circuit was evoked by direct tactile siphon stimulation using a stimulator-driven "tapper" (a glass probe attached to a modified electrical relay). Stimuli consisted of taps 60 $\mathrm{msec}$ in duration delivered to the approximate center of the outer surface of the siphon. The net evoked activity of the SWR circuit was monitored as polysynaptic (complex) EPSPs in identified LFS motor neurons, which were hyperpolarized $30 \mathrm{mV}$ from rest to prevent action potentials. LFS neurons could be uniquely identified by visually monitoring siphon movements induced by intracellular activation of the neurons, since they mediate characteristic movements that are either directed anteriorly (LFS ${ }_{A}$ cells) or posteriorly (LFS ${ }_{B}$ cells) (Frost et al., 1988). Identification criteria for the interneurons examined in this study are given in the Results.

\section{Experimental procedures and quantitative measures}

Complex EPSP in the LFS motor neurons. To gain insights into interneuronal processing in the SWR network, a primary goal of this study 
Figure 2. Voltage-clamp inactivation of $L 29$ reduces the net tap-evoked input to LFS motor neurons. $A$, Example of an L29 voltage-clamp experiment. The top row of traces are tap-evoked responses (arrows) recorded from an identified LFS motor neuron (hyperpolarized to prevent action potentials). The bottom row of traces are simultaneous recordings from an L29 interneuron; both voltage $\left(V_{m}\right)$ and current $\left(I_{m}\right)$ traces are shown. Following two baseline stimuli (the second is shown at $0: 00 \mathrm{~min}$, $\mathrm{L} 29$ was voltage clamped at resting potential (clamp trial, 5:00 $\min$ ); this resulted in a $40 \%$ reduction in area of the motor neuron complex EPSP (dashed line represents peak baseline response). When $\mathrm{L} 29$ was again allowed to fire (recovery trial, 10:00 $\mathrm{min}$ ), the motor neuron response returned to baseline levels. $B$, Summary of quantitative data from voltage-clamp experiments. As a measure of the net motor neuron response in this and subsequent experiments, the area underneath the initial $500 \mathrm{msec}$ of the tap-evoked EPSP was integrated (see Materials and Methods); data are normalized to the mean of two baseline trials, and expressed as means \pm SEM. The complex EPSP in LFS motor neurons was significantly reduced during voltage clamp of a single L29;5 min recovery trials were not different from baseline values. ${ }^{*}, p<0.05$ compared to baseline; $N=13$.

A

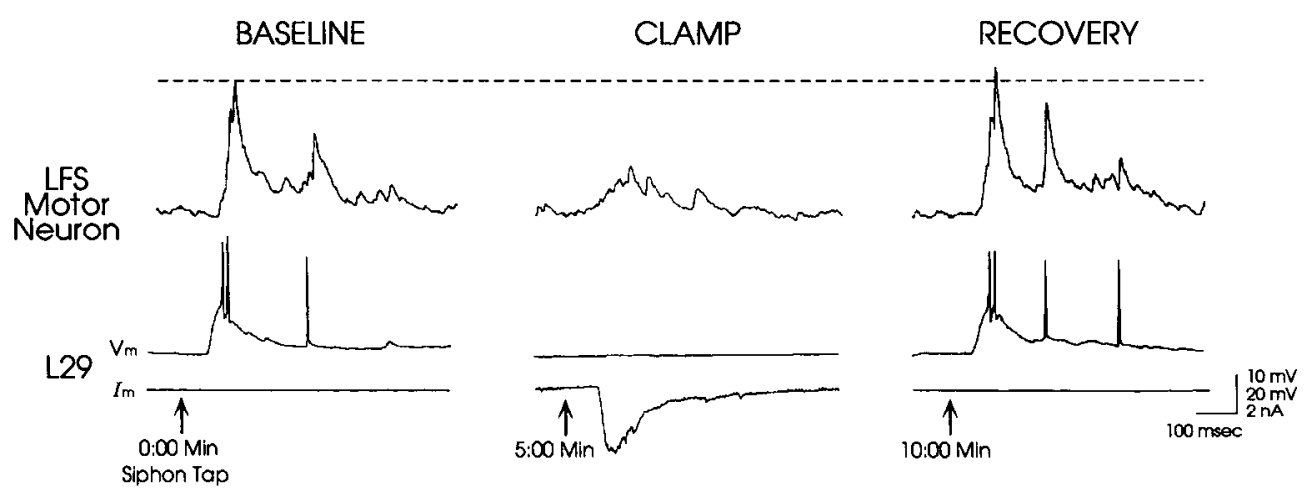

B

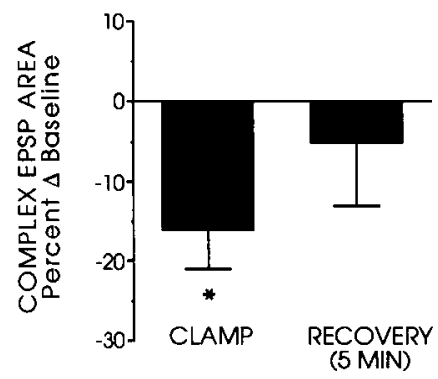

was to determine how the activity of single, identified interneurons can modify the output of the network, as measured in LFS siphon motor neurons. Also of interest was to determine the time course of activityinduced modifications of siphon motor neuron responses. To address these questions, the following general procedure was employed. Each animal was used for only a single experiment. A total of five tactile stimuli (see Fig. $1 A$ ) were delivered to the siphon at a 5 min interstimulus interval (ISI): two baseline trials, followed by a test trial, and then two recovery trials. In control experiments, siphon taps delivered at this ISI did not lead to decrement of the complex EPSP in LFS neurons. Prior to the test trial, an identified interneuron (either L29 or L30) was activated for $5 \mathrm{sec}$ by injection of depolarizing current. The timing of intracellular activation was set so the cessation of firing preceded the test trial by an interval of 10,20 , or $40 \mathrm{sec}$. The $20 \mathrm{sec}$ interval was used in most experiments; 10 or $40 \mathrm{sec}$ intervals were used to assess the time course of modulation produced by interneuron activation. Sufficient current (2-8 nA) was injected to activate the interneuron maximally; the rate of firing obtained was typically less than that which can be attained using stimuli applied directly to the body surface (Hawkins and Schacher, 1989; T. M. Fischer and T. J. Carew, unpublished observations). Since we observed no significant difference between the two recovery trials for any set of experiments, only values for the first recovery trial are presented.

As a quantitative measure of net SWR activity, the area underneath the initial $500 \mathrm{msec}$ of the evoked motor neuron complex EPSP (the approximate duration of the response to the $60 \mathrm{msec}$ tap) was integrated (in $\mathrm{mV} \cdot \mathrm{msec}$ ) using a PC-based physiological analysis software package (SPIKE, Hilal Associates, Englewood Cliffs, NJ). This particular measure was used because it is sensitive to changes of both the amplitude and duration of the motor neuron complex EPSP. Test and recovery responses are expressed as a percentage of the mean of the two pretest baseline trials (thus scores of $0 \%$ signify no change in the response compared to baseline). Statistical significance was assessed using $t$ tests for repeated measures; all probability values reported are two tailed.

Monosynaptic IPSP from L30 to L29. In one set of experiments, we investigated the activity-induced plasticity of the monosynaptic inhib- itory connection from interneuron $\mathrm{L} 30$ to interneuron L29. These experiments followed the same general protocol as described above, with the exceptions that a $1 \mathrm{~min}$ ISI was used, and only three trials (baseline, test, recovery) were given for each test interval examined. In general, we attempted a complete interval analysis for each preparation, examining test intervals of $10,20,30$, and $40 \mathrm{sec}$. Within a preparation, for each interval examined there was an independent series (baselinetest-recovery) run, with at least 3 min separating each series. The order in which the intervals were tested was varied between preparations. A complete interval analysis was often not possible for each preparation. When this was the case, all intervals successfully measured were included in the analysis. Each interval was examined only once in a preparation; thus, the group data obtained for each interval consist of uncorrelated (independent) observations.

For measurement of monosynaptic IPSPs, the peak amplitude of the synaptic response in $L 29$ was measured using the same PC-based system as described above. These data are expressed as a difference score (in $\mathrm{mV}$ ) from baseline trials. All summary data are presented as mean difference \pm standard errors of the mean. Statistical significance was assessed using $t$ tests for repeated measures; all probability values reported are two tailed.

\section{Results}

Identification of $L 29$

It was particularly important in this study to identify the interneuron L29 accurately and consistently. Candidate interneurons were initially identified by size, color, and positional criteria (Hawkins et al., 1981a). In addition, the use of threc characteristic features of L29 cellular responses (shown in Fig. 1) permitted unambiguous identification of this interneuron. First, as previously described (Hawkins et al., 1981a; Frost et al., 1988), direct intracellular activation of L29 recruits a series of IPSPs back onto itself. These recurrent IPSPs cause a "stuttering" 


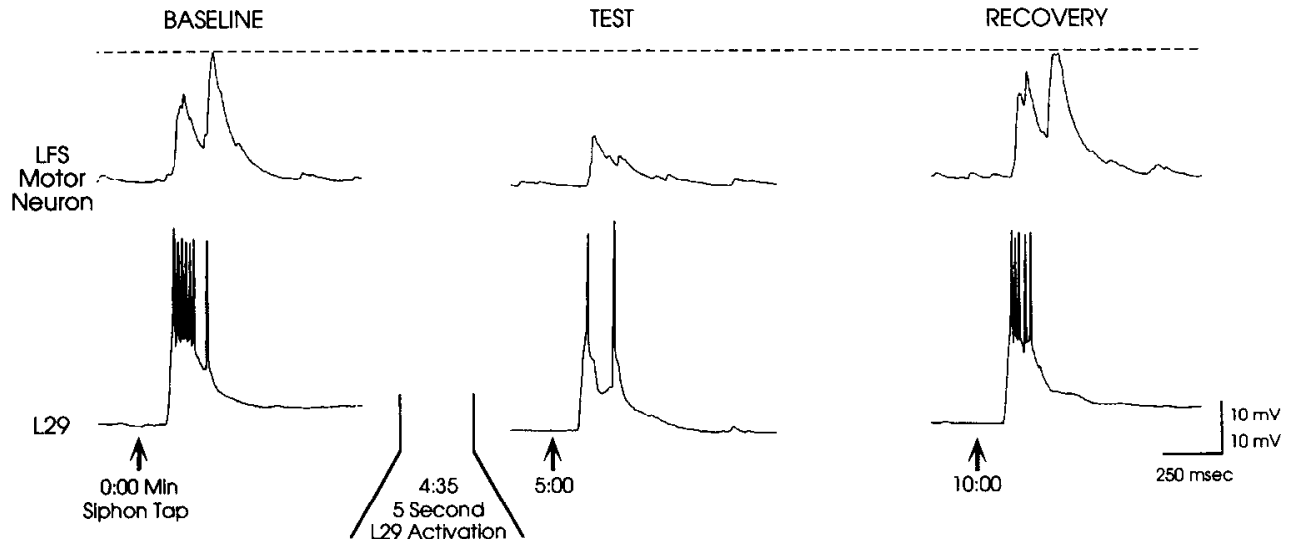

pattern of action potential activity in L29 during prolonged depolarization (Fig. 1C). Second, injection of depolarizing current into $\mathrm{L} 29$ that is below threshold for producing action potentials can also elicit recurrent IPSPs (Fig. $1 D$ ). Third, brief $(60 \mathrm{msec})$ taps to the siphon evoke a characteristic phasic, highfrequency burst of two to eight action potentials in L29 (Fig. $1 B$ ). This burst terminates rapidly, usually within $500 \mathrm{msec}$; tactile stimuli with a duration greater than $500 \mathrm{msec}$ typically evoke a second burst (off response). This response profile is consistent with observations that L29 responds optimally to moving stimuli within its receptive field. We have observed up to four neurons in a single abdominal ganglion that meet these cellular criteria, though we made no systematic attempt to search for additional cells.

\section{L29 provides significant excitatory input to LFS motor neurons}

It has previously been shown that L29 has an excitatory monosynaptic connection to an identified class of siphon motor neurons, the LFS motor neurons (Frost et al., 1988). We have further characterized this synapse by measuring the amplitudes of the L29 EPSP in the two identified LFS subtypes, LFS $_{A}$ and LFS $_{B}$ motor neurons, in a number of preparations. These measurements (data not shown) were made with the motor neuron hyperpolarized by $30 \mathrm{mV}$ from rest to prevent action potentials. On average, the amplitude of the monosynaptic EPSP was large in both subtypes $\left(\operatorname{LFS}_{\mathrm{A}}: \bar{x}=8.8 \pm 1.4 \mathrm{mV}, n=13 ; \mathrm{LFS}_{\mathrm{B}}: \bar{x}=\right.$ $10.0 \pm 1.5 \mathrm{mV}, n=14)$. The strength of the L29 EPSP is often sufficient to produce an action potential when the motor neuron is at resting potential. In a few cases, however, we observed L29 interneurons that had little or no discernable direct input to the LFS motor neurons. Thus, although the L29 interneuron pool has extremely similar cellular characteristics (Fig. 1), different members of the pool can vary in the strength of their synaptic output to motor neurons. Finally, L29 appears to provide equivalent input to both $\mathrm{LFS}_{\mathrm{A}}$ and $\mathrm{LFS}_{\mathrm{B}}$ cells; there was no significant difference observed between the amplitude of the L29 EPSP and type of LFS motor neuron $\left(t_{24}=0.34, p=0.74\right)$.

We were interested in determining the net contribution of a single L29 to the complex EPSP in these motor neurons evoked by a tap to the siphon. To examine this question, we performed a series of voltage-clamp experiments (Fig. 2). Siphon taps were delivered at a 5 min ISI. Following two baseline stimuli, L29
Figure 3. Intracellular activation of 1.29 inhibits tap-evoked complex EPSPs in LFS motor neurons. The top row of traces are tap-evoked responses in an identified LFS motor neuron (hyperpolarized to prevent action potentials); the bottom row of traces are simultaneous responses recorded in L29. Following two baseline trials (the second is shown at 0:00 $\mathrm{min}$ ), $\mathrm{L} 29$ is intracellularly activated for a $5 \mathrm{sec}$ period at a rate of approximately $30 \mathrm{~Hz}$ (4:30 min, not shown). Twenty seconds following this activation (test trial, 5:00 $\mathrm{min}$ ), both the tap-evoked complex EPSP and the number of $L 29$ spikes are reduced (dashed line indicates a peak baseline response). Both recover to baseline levels 5 min later (recovery trial, 10:00 $\min$ ). was voltage clamped at resting potential (approximately -60 $\mathrm{mV}$ ), which was effective in functionally removing it from the SWR circuit (see Discussion). An example is shown in Figure $2 B$, which illustrates that voltage-clamp inactivation of a single L29 interneuron can significantly reduce the net excitatory input to LFS motor neurons. In the experiment shown, the area of the complex EPSP was reduced by $40 \%$ (compared to baseline); at the next trial the complex EPSP returned to baseline levels. A summary of 13 experiments is shown in Figure $2 B$; these experiments were performed without regard to the size of the L29 monosynaptic EPSP onto the motor neuron. These data demonstrate that the complex EPSP is significantly reduced when a single L29 is functionally removed from the SWR circuit through voltage clamp $\left(\bar{x}=-14 \pm 5 \%, t_{12}=-2.63, p<0.02\right)$; 5 min recovery trials were not different from baseline values $(\bar{x}$ $=-5 \pm 8 \%, t_{12}=-0.66, p=0.52$ ). Taken together with the results examining the monosynaptic EPSP from L29 to the motor neurons described above, these data demonstrate that L29 interneurons comprise a significant excitatory input pathway to LFS motor neurons.

\section{Intracellular activation of L29 inhibits siphon tap-evoked complex EPSPS in LFS motor neurons}

In light of the significant excitatory input of L29 described above, and the previously documented facilitatory effects resulting from L29 activation (Hawkins et al., 1981b), we were surprised to find that direct intracellular activation of L29 produces a transient inhibition of the tap-evoked complex EPSP in LFS motor neurons. An example of the kind of experiment we performed to examine this effect is shown in Figure 3. Following baseline trials, L29 was depolarized for $5 \mathrm{sec}$, producing an average firing rate of $30 \mathrm{~Hz}$ (a discharge of this frequency and duration is readily produced in $\mathrm{L} 29$ by a moving tactile stimulus to the tail, a stimulus that produces marked inhibition of the SWR; see Discussion). The complex EPSP was then examined $20 \mathrm{sec}$ following L29 activation (test trial). Two typical effects resulting from L29 activation are illustrated: first, the motor neuron complex EPSP was substantially reduced, in this case a reduction in area of $70 \%$. The tap-evoked EPSP recovers to baseline levels $5 \mathrm{~min}$ later. Second, the number of I 29 spikes were also reduced (from seven spikes to two spikes); this response also recovers 5 min later. Comparable results were obtained in 11 additional experiments (summarized in Fig. 5), in which the complex EPSP 
Figure 4. L29 activation induces a reduction of tap-evoked responses of other (nonactivated) L 29 interneurons. The same protocol was used as in Figure 3, except that tap-evoked responses were recorded simultaneously from two L29 interneurons, denoted L29, (top row of traces) and $L 29_{2}$ (bottom row of traces). Following baseline trials (the second is shown at 0:00 $\mathrm{min}$ ), $\mathrm{L} 29_{2}$ was activated intracellularly for a $5 \mathrm{sec}$ period (4:35 min, inset). When $\mathrm{L} 29_{2}$ is activated, L29, does not fire; in fact, a barrage of IPSPS is recruited onto $L 29_{1}$. Twenty seconds following activation $(5: 00 \mathrm{~min})$, the number of evoked spikes in both L29 interneurons is reduced. Both responses recover to baseline levels $5 \mathrm{~min}$ later (10:00 min).
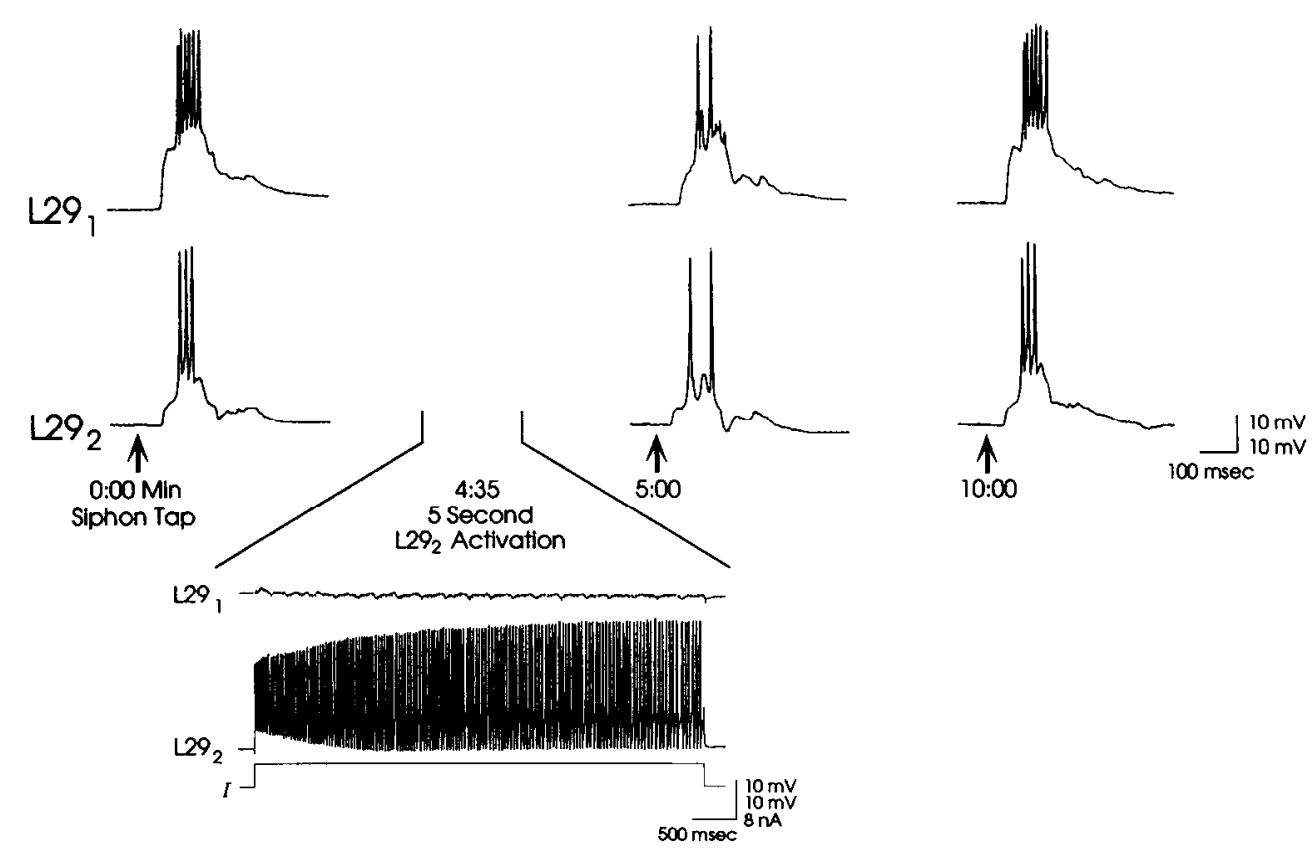

in the motor neuron was significantly reduced $20 \mathrm{sec}$ following L29 activation $\left(\bar{x}=-21 \pm 6 \%, t_{11}=-3.17, p<0.01\right)$. Significant recovery was observed $5 \mathrm{~min}$ later; the complex EPSPs were no longer significantly different from baseline $(\bar{x}=-7 \pm$ $\left.4 \%, t_{11}=-1.78, p=0.10\right)$. Concurrently, the number of L29 spikes was also significantly reduced at $20 \mathrm{sec}$ test trials $(\bar{x}=$

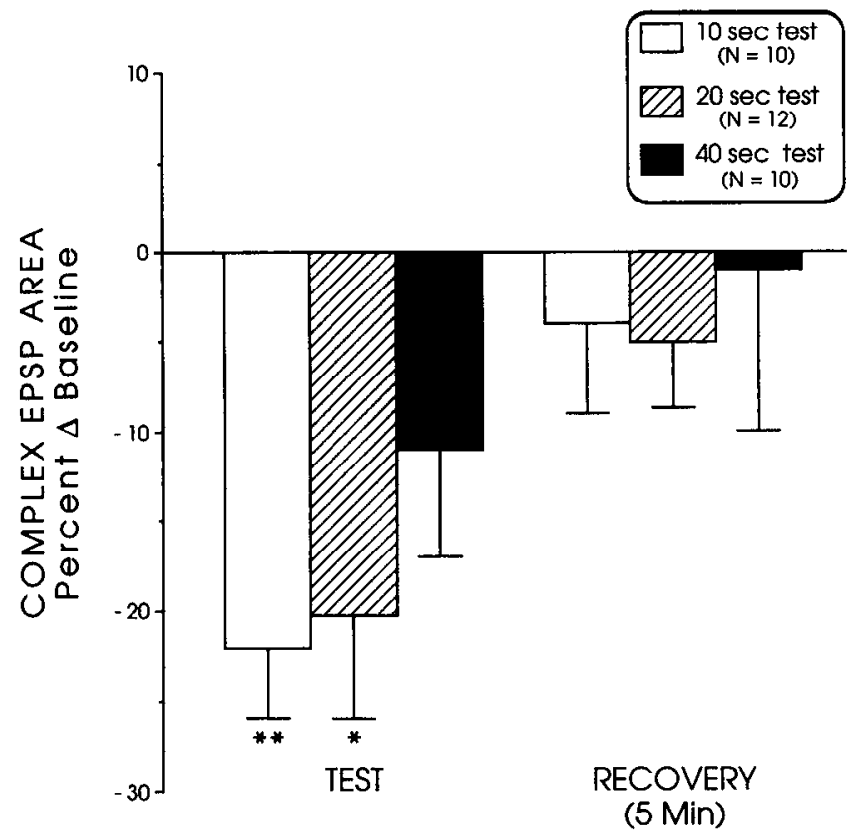

Figure 5. Summary of experiments examining the time course of L29induced inhibition of tap-cvoked LFS motor neuron responses. Motor neuron responses were tested either 10, 20, or $40 \mathrm{sec}$ following L29 activation. Significant inhibition of the tap-evoked motor neuron complex EPSP was found at $10 \mathrm{sec}$ and $20 \mathrm{sec}$ tests, but not for the $40 \mathrm{sec}$ test. Recovery trial measures for all three groups were not significantly different from their respective baseline measures. ${ }^{* *}, p<0.001 ;{ }^{*}, p<$ 0.01 ; compared to baseline.
$-1.5 \pm 0.5$ spikes, $t_{11}=-3.25, p<0.01$ ), and recovered $5 \mathrm{~min}$ later $\left(\bar{x}=-0.1 \pm 0.4\right.$ spikes, $\left.t_{11}=-0.31, p=0.76\right)$.

One possible explanation for L29-induced inhibition is that intracellular activation itself induces an intrinsic change in L29 (e.g., it becomes refractory), which in turn reduces its response to tap-evoked input, thus diminishing its net effective output to the motor neuron. Two types of results suggest that this is not the case. First, we observed a number of instances in which the complex EPSP is significantly reduced by the prior activation of an L29 interneuron that itself had no discernable input to the motor neuron. In fact, in the experiment shown in Figure 3 , there was no observable synaptic connection between the L29 interneuron and the LFS motor neuron. Thus, even if that individual L29 were intrinsically inactivated, removing that L29 alone would unlikely reduce the complex EPSP by such an extent $(70 \%)$. Second, we have found that intracellular activation of one $\mathrm{L} 29$ results in a decreased tap-evoked response of other (nonactivated) L29 interneurons. An example is shown in Figure 4. The protocol in this experiment is the same as above, except the tap-evoked response of one (nonactivated) L29 interneuron (L29) is examined $20 \mathrm{sec}$ following the activation of another $\mathrm{L} 29\left(\mathrm{~L} 29_{2}\right)$. The inset demonstrates that when $\mathrm{L} 29_{2}$ is driven, L29, does not fire; in fact, a barrage of recruited IPSPs is observed in the L29, trace (see below). At the test tap (20 sec following L29 2 activation), the number of evoked spikes in both interneurons is decreased, recovering $5 \mathrm{~min}$ later. This experiment was repeated in two additional preparations and the same results were obtained. Taken together, these results suggest a heterosynaptic mechanism of inhibition that is invoked by L29 activation, one effect of which is the reduction of tap-evoked activity in the L29 interneuronal pool.

Wc determined the time course of L29-induced inhibition by examining, in separate experiments, the complex EPSP in LFS motor neurons either 10,20 or $40 \mathrm{sec}$ following L29 activation (the $20 \mathrm{sec}$ test data were described above). These results are summarized in Figure 5. The largest reduction of the tap-evoked complex EPSP was observed in the 10 sec test $(\bar{x}=-22 \pm 3 \%$, 
A
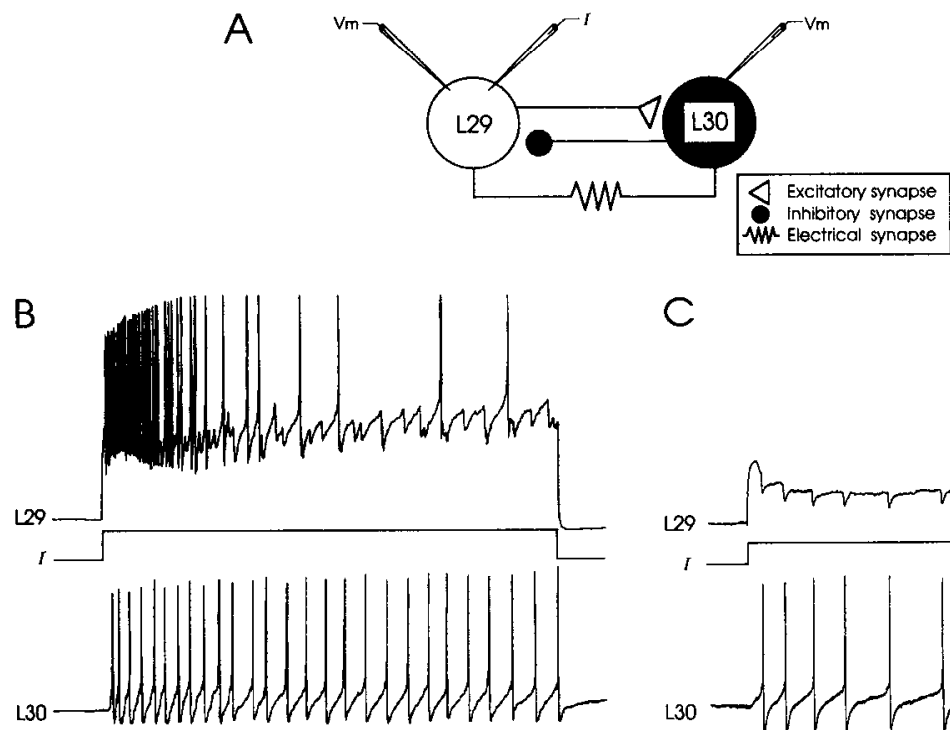

C

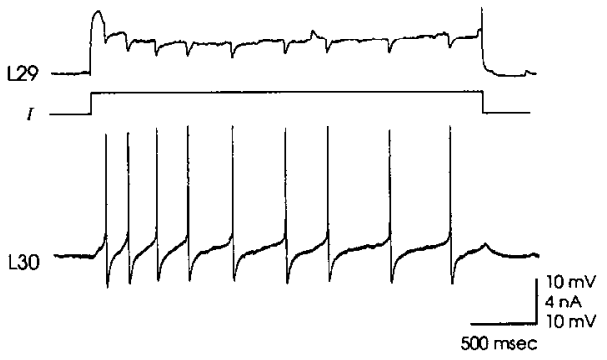

Figure 6. Synaptic relationship between interneurons L29 and L30. A, Schematic of the known synaptic connectivity between L29 and L30. L29 makes an excitatory monosynaptic connection onto L30; L30 in turn makes a recurrent inhibitory monosynaptic connection onto $L 29$. In addition, these cells are connected via an electrical synapse. $B$, Direct intracellular activation of $\mathrm{L} 29$ (top trace) activates $\mathrm{L} 30$, which in turn provides recurrent inhibitory input to L29. C, Injection of subthreshold current into $\mathbf{L} 29$ can also activate L30 via the electrical synapse between these neurons. Note the transient in L30 when the current pulse in L29 is terminated. $t_{9}=-6.99, p<0.001$ ), with progressively smaller reductions at longer testing intervals. Although the reduction observed in the $40 \mathrm{sec}$ test is not statistically significant $\left(\bar{x}=-11 \pm 6 \%, t_{9}\right.$ $=-1.72, p=0.12$ ), there is a clear trend toward a reduced response; in 5 out of 10 experiments the test complex EPSP was at least $10 \%$ less than baseline. Five minute recovery trials for all test groups were not significantly different from their respective baseline measures (10 sec test: $\bar{x}=-3 \pm 4 \%, t_{9}=$ $-0.69, p=0.51 ; 40$ sec tests: $\bar{x}=-1 \pm 9 \%, t_{9}=-0.12, p=$ 0.91 ). The results shown in Figure 5 thus indicate that L29induced inhibition is maximal immediately following L29 activation, and recovers toward baseline values with a time course of up to $40 \mathrm{sec}$.

The results described thus far demonstrate that $L 29$ activation produces a transient reduction of tap-evoked input to LFS motor neurons, which is mediated through the recruitment of inhibition into the SWR circuit. This inhibitory process appears to work in part through reducing the responsiveness of the L29 interneuronal pool, thereby diminishing the contribution of this significant source of excitatory input to siphon motor neurons. A prime candidate for the mediation of this inhibition is the inhibitory interneuron L30, which is the identified source of the recurrent IPSPs produced by L29 activation (Hawkins et al., 1981a).

\section{Identification of $\mathrm{L} 30$}

Figure $6 A$ illustrates the previously described synaptic relationship between I.29 and L.30 (Hawkins et al., 1981a). L29 has an excitatory monosynaptic connection to L30; L30 in turn has a recurrent inhibitory monosynaptic connection onto L29. In addition, they are connected via an electrical synapse. Both cells also receive direct excitatory input from siphon sensory neurons (not shown). Figure $6, B$ and $C$, shows examples of physiological responses illustrating the synaptic relationships, which were used here as criteria for $\mathrm{L} 30$ identification. In Figure $6 B$, intracellular activation of L29 is shown to activate L30, which in turn is the source of the recurrent IPSPs seen in L29. In Figure $6 C$, we show that passing depolarizing current into L29, which is sub- threshold for its own spike initiation, activates L30 via the electrical synapse between these cell types (see also Fig. $1 D$ ). This shows that the voltage threshold for action potential initiation is lower in L30 than in L29, and that L29 can activate L30 even when the depolarization in L29 is below threshold for the initiation of its own action potentials. We have identified two L30 neurons in the same abdominal ganglion that meet these criteria, though we made no attempt to carry out a systematic search for additional cells.

\section{Direct L30 activation mimics L29-induced inhibition}

The synaptic relationship between L29 and L30 (Fig. 6) suggested a likely candidate mechanism for L29-induced inhibition: L29 may produce inhibition through the recruitment of L30, which in turn inhibits the $\mathrm{L} 29$ interneuronal pool. If this were the case, then direct activation of L30 should result in similar inhibitory effects as activation of L29; that is, it should produce reductions of both $\mathrm{L} 29$ action potentials and tap-evoked complex EPSPs in LFS motor neurons. To test this hypothesis directly, we performed an experiment similar to that used to examine L29-induced inhibition (see Fig. 3), but instead activated L30 prior to examining tap-evoked L29 and LFS responses. An example of our results is shown in Figure 7. As shown in the inset of Figure 7, L30 activation (at a rate of $11.4 \mathrm{~Hz}$ ) produces a series of IPSPs in L29; however, L30 has no discernable effect on the motor neuron (Fig. 7, inset). Yet when examined $20 \mathrm{sec}$ following intracellular activation of L30, the tap-evoked complex EPSP in LFS motor neurons is markedly reduced, as is the number of spikes in L29. Both of these inhibitory effects recover 5 min later. A summary of a series of these experiments is shown in Figure 8. Twenty seconds following direct activation of L30, we observed a significant reduction in both the evoked LFS motor neuron complex EPSP (Fig. $9 A ; \bar{x}=-24 \pm 7 \%, t_{7}=$ $-3.22, p<0.01)$ and the number of L29 spikes $(\bar{x}=-1.9 \pm$ 0.6 spikes, $\left.t_{5}=-3.14, p<0.05\right)$. As with L29-induced inhibition, this inhibitory effect of $L 30$ recovers within 5 min: responses in the $5 \mathrm{~min}$ recovery trials were not significantly different from baseline for either measure (LFS complex EPSP: $\bar{x}$ 
Figure 7. Direct intracellular activation of L30 mimics L29-induced inhibition. The three rows of traces are tap-evoked responses in an LFS motor neuron (top trace; hyperpolarized), L29 (middle trace), and L30 (bottom trace). The experimental protocol is similar to that used to examine L29-induced inhibition (see Figs. 3, 4). Following two baseline trials (the second baseline trial is shown at time $0: 00 \mathrm{~min}$ ), $\mathrm{L} 30$ was activated for a $5 \mathrm{sec}$ period (4:35, inset). Note that L30 has no discernable input to the motor neuron. Twenty seconds following L30 activation (test trial, 5:00 $\mathrm{min}$ ), the responses of both the motor neuron and L29 are markedly reduced (dashed line indicates peak baseline response). Both responses recover to baseline levels $5 \mathrm{~min}$ later (recovery trial, 10:00 min).

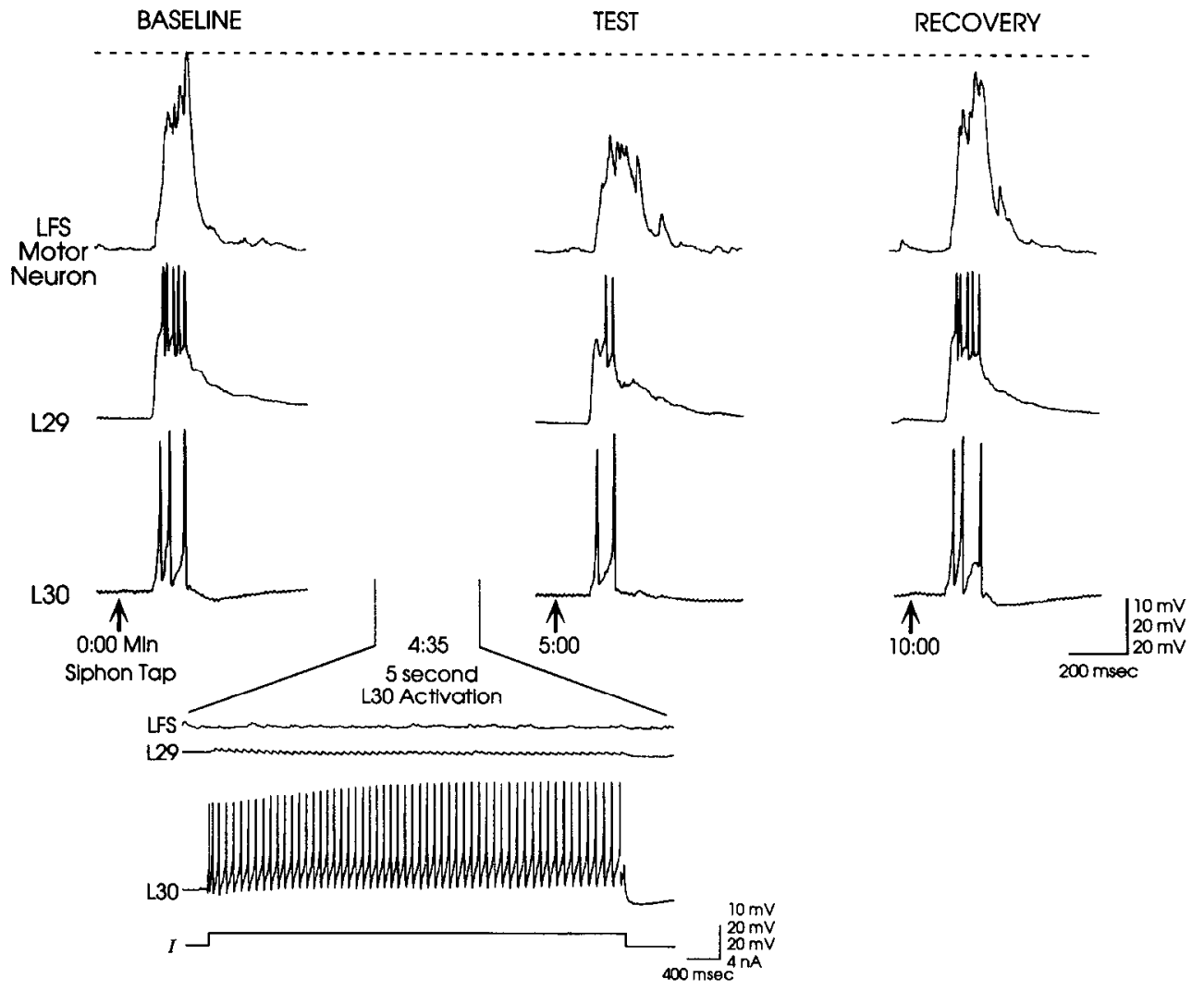

$=4 \pm 4 \%, t_{7}=1.00, p=0.35 ;$ L29 spikes: $\bar{x}=-0.25 \pm 0.3$ spikes, $\left.t_{5}=-0.81, p=0.46\right)$. These data demonstrate that direct activation of $L 30$ produces similar inhibitory effects as seen with L29 activation. Since L30 has no apparent input to LFS motor neurons, a likely site for this inhibitory modulation is the inhibitory synapse from L30 onto L 29 .

\section{L30 shows activity-dependent enhancement of inhibitory synaptic transmission}

To explore the mechanism underlying L30-induced inhibition (Figs. 7, 8), we examined the L30 monosynaptic IPSP onto L29 and found that it is modified in an activity-dependent fashion. An example of our experiments is illustrated in Figure $9 \mathrm{~A}$. The magnitude of the IPSP onto L29 was examined at $1 \mathrm{~min}$ intervals by eliciting a single action potential in L30. To aid in measure- ment, L29 was hyperpolarized to a level $30 \mathrm{mV}$ below rest to invert the IPSP (thus it is seen as a depolarizing potential in Figs. 9, 10); the reversal potential of the IPSP is near L29's resting potential (approximately $-55 \mathrm{mV}$ ). To examine activitydependent alterations in synaptic strength, L30 was activated for $5 \mathrm{sec}$ as in previous experiments, and the size of the monosynaptic IPSP was tested $20 \mathrm{sec}$ later. The examplc shown in Figure $9 A$ is a typical result. Initially, the size of the IPSP was relatively small (less than $2 \mathrm{mV}$ ); however, $20 \mathrm{sec}$ following L30 activation the synapse exhibited a dramatic (fivefold) enhancement in amplitude. One minute following this test trial, the size of the IPSP returned to baseline levels (not shown). This experiment thus demonstrates that L30's inhibitory synapse exhibits a significant potentiation following activation (indicated by asterisk, Fig. 9A). While this type of synaptic facilitation
Figure 8. Summary of experiments examining $\mathrm{L} 30$-induced inhibition of tap-evoked LFS motor neuron and L29 responses. $A$, Summary of data for LFS motor neuron responses $(N=8)$. Twenty seconds following $\mathrm{L} 30$ activation (TEST trial), a significant reduction of the tap-evoked motor neuron complex EPSP was observed. Five minute recovery trials were not significantly different from baseline. $B$, Summary of data for L29 responses $(N=6)$. Twenty seconds following $\mathrm{L} 30$ activation (TEST trial), a significant reduction of the number of tap-evoked L29 spikes was observed. Five minute recovery trials were not significantly different from baseline. ${ }^{* *}, p<0.01 ;^{*}, p<0.05$; compared to baseline.
A

Motor Neuron Complex PSP

B

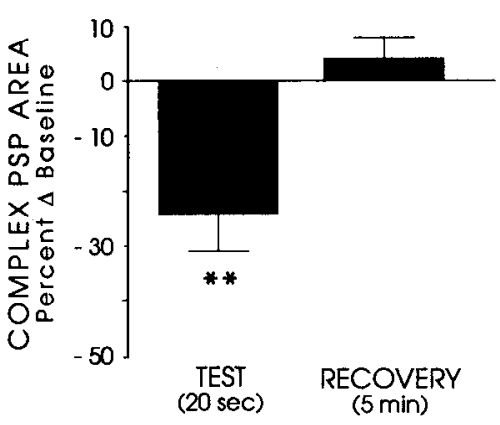


A

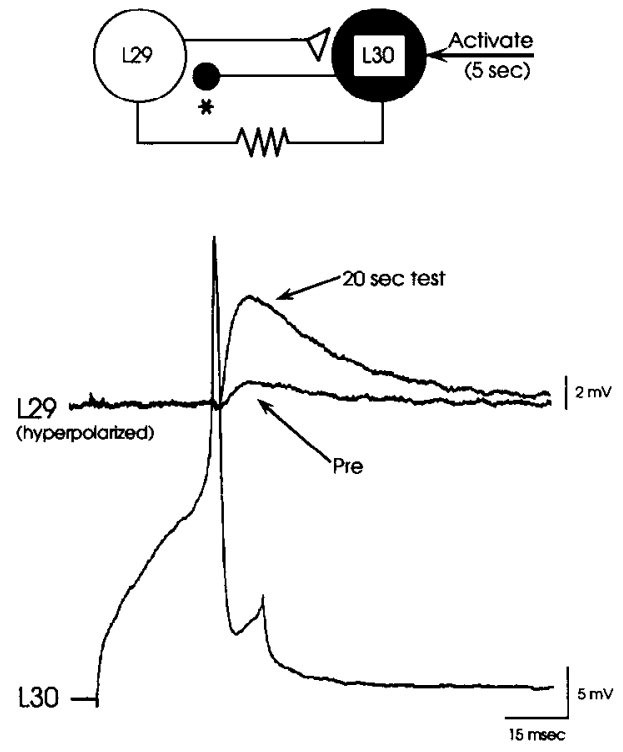

B

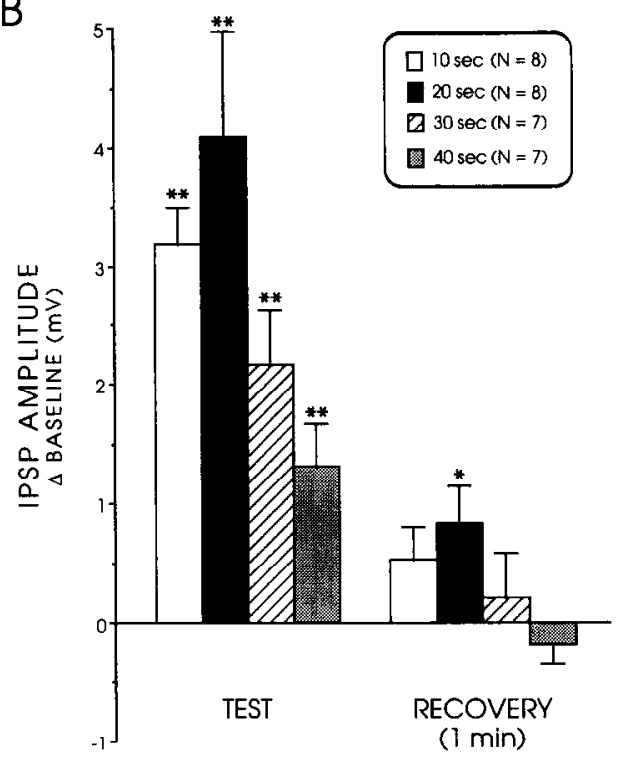

Figure 9. The L30 IPSP onto L29 exhibits activity-dependent facilitation. $A$, The L30 IPSP onto L29 was examined at $1 \mathrm{~min}$ intervals by generating a single action potential in L 30 (only one is shown). L29 was hyperpolarized to a level $30 \mathrm{mV}$ below rest to invert the IPSP (the reversal potential is near rest); thus, the IPSP is seen as a depolarizing synaptic potential. L29 responses are shown superimposed. Initially, the magnitude of the IPSP is relatively small (Pre). Twenty seconds following direct L30 activation (see schematic at top), the size of the IPSP is substantially larger $(20 \mathrm{sec}$ test $)$. The IPSP recovers to near baseline values $1 \mathrm{~min}$ later (recovery trial, not shown). $B$, Summary of the time course of activity-dependent synaptic potentiation of the L30 IPSP. The amplitude of the monosynaptic L30 IPSP was measured $10,20,30$, or 40 sec following direct L30 activation. These measures, as well as those from recovery tests ( $1 \mathrm{~min}$ following $\mathrm{L} 30 \mathrm{ac}$ tivation), are expressed as difference scores from pretest measures. ${ }^{* *}, p<$ $0.01 ; *, p<0.05$; compared to baseline. formally can be described as "posttetanic potentiation" (Kretz et al., 1984), we prefer the term "activity-dependent potentiation" to reflect the fact that this synapse can be enhanced at very low (nontetanic) rates of activation (see below).

A summary of a series of experiments carried out to determine the time course of activity-dependent synaptic potentiation in L30 is shown in Figure $9 B$. In these experiments, the amplitude of the monosynaptic IPSP from L30 to L29 was measured 10, 20,30 , or $40 \mathrm{sec}$ following direct $\mathrm{L} 30$ activation. At all four test intervals, statistically significant incrcases in the amplitude of the L30 IPSP were observed (10 sec: $\bar{x}=3.2 \pm 0.3 \mathrm{mV}, t_{7}=$ $10.16, p<0.001 ; 20 \mathrm{sec}: \bar{x}=4.1 \pm 0.9 \mathrm{mV}, t_{7}=4.64, p<$ $0.01 ; 30$ sec: $\bar{x}=2.2 \pm 0.5 \mathrm{mV}, t_{6}=4.64, p<0.01 ; 40$ sec: $\bar{x}$ $=1.3 \pm 0.4 \mathrm{mV}, t_{6}=3.70, p<0.01$ ). Measures in the $1 \mathrm{~min}$ recovery trials for 10,30 , and $40 \mathrm{sec}$ tests were not significantly different from baseline ( $10 \mathrm{sec}: \vec{x}=0.5 \pm 0.3 \mathrm{mV}, t_{7}=1.87, p$ $=0.10 ; 30 \mathrm{sec}: \bar{x}=0.2 \pm 0.4 \mathrm{mV}, \iota_{6}=0.57, p=0.59 ; 40 \mathrm{sec}:$ $\left.\bar{x}=-0.2 \pm 0.2 \mathrm{mV}, t_{6}=-1.21, p=0.27\right)$. In the $20 \mathrm{sec}$ recovery trial, although the amplitude of the IPSP was markedly reduced, there was still a significant difference from baseline $(\bar{x}=0.8 \pm$ $0.3 \mathrm{mV}, t_{7}=2.64, p<0.05$ ). These data demonstrate that activation of $\mathrm{L} 30$ results in a significant potentiation of its monosynaptic IPSP, which has a time course of at least $40 \mathrm{sec}$, similar to the time course of L29-induced inhibition of the motor neuron complex EPSP (Fig. 5). This suggests that the mechanism of response inhibition seen when $L 30$ is activated (directly or through L29 activation) is through potentiation of L30 inhibitory synaptic transmission.

If, as we propose, activation of L29 induces inhibition in the SWR circuit through the subsequent activation (and potentiation) of synaptic transmission from L 30, then activation of L29 itself should drive L30 sufficiently to result in a potentiation of the L30 IPSP. To test this hypothesis, we carried out a series of experiments shown in Figure $10 \mathrm{~A}$. The protocol was the same as the experiment shown in Figure 9, except the L30 monosynaptic IPSP was examined $20 \mathrm{sec}$ following activation of L29. During L29 activation, L30 was observed to spike (not shown), albeit at a lower frequency than that attainable with direct L 30 activation. Following L29 activation, a threefold enhancement of the IPSP over the baseline response was observed. The size of the IPSP returned to baseline levels $1 \mathrm{~min}$ later. Activation of L29 can thus generate sufficient activity in L30 to potentiate the L30 IPSP.

Figure $10 B$ is a summary of experiments performed to determine the time course of $\mathrm{L} 30$ potentiation produced by L29 activation. As before (Fig. 9), the amplitude of the L30 IPSP was measured $10,20,30$, or $40 \mathrm{sec}$ following L29 activation. The data are qualitatively similar to those obtained using direct L30 activation (Fig. 9B); significant increases in the amplitude of the L30 IPSP were observed at all four test intervals (10 sec: $\bar{x}=2.3 \pm 0.4 \mathrm{mV}, t_{7}=5.47, p<0.001 ; 20 \mathrm{sec}: \bar{x}=1.7 \pm 0.3$ $\mathrm{mV}, t_{8}=5.91, p<0.001 ; 30 \mathrm{sec}: \bar{x}=1.3 \pm 0.3 \mathrm{mV}, t_{5}=4.34$ $p<0.01 ; 40$ sec: $\left.\bar{x}=0.4 \pm 0.1 \mathrm{mV}, t_{8}=-1.09, p<0.01\right)$. Measures in $1 \mathrm{~min}$ recovery trials were not significantly different from baseline $\left(10 \mathrm{sec}: \bar{x}=0.2 \pm 0.4 \mathrm{mV}, t_{7}=0.54, p=0.60\right.$ 20 sec: $\bar{x}=0.3 \pm 0.1 \mathrm{mV}, t_{8}=2.12, p=0.07 ; 30 \mathrm{sec}: \bar{x}=0.1$ $\pm 0.3 \mathrm{mV}, t_{5}=0.12, p=0.91 ; 40 \mathrm{sec}: \bar{x}=-0.1 \pm 0.1 \mathrm{mV}, t_{8}$ $=-1.09, p=0.31$ ). The magnitude of $\mathrm{L} 30$ potentiation observed in these experiments is less than that obtained using direct L30 activation (note difference in scale in Figs. 9B, 10B). This is primarily due to the higher firing rates of L30 that are attained through direct activation. Consistent with this, we found a significant correlation between the rate of $\mathrm{L} 30$ activation and percentage change in the L30 IPSP, using a combined data set from both direct (Fig. 9B) and indirect (Fig. 10B) L30 activation experiments (regression analysis: $R^{2}=0.20, p<0.01$ ). These data show that the L30 IPSP is potentiated in an activity-dependent fashion. Further, this enhancement is attainable even at low rates of activation; we have observed significant potentiation of the L30 IPSP with activity rates in L30 as low as 1.8 $\mathrm{Hz}$.

\section{Discussion}

Modulation of the siphon withdrawal response

The Aplysia SWR has been extensively studied as a model system for the analysis of neural control of behavior and behavioral 
Figure 10. The L30 IPSP is potentiated following activation of L29. A, The L30 IPSP onto L29 was examined at $1 \mathrm{~min}$ intervals by generating a single action potential in L30 (only onc is shown). L29 was hyperpolarized to a level $30 \mathrm{mV}$ below rest to invert the IPSP (data as in Fig. 9). Initially, the magnitude of the IPSP is relatively small (Pre). Twenty seconds following direct intracellular activation of L29 (see schematic at top), the size of the L30 IPSP is larger (20 sec test). The IPSP recovers to near baseline values $1 \mathrm{~min}$ later (recovery trial, not shown). $B, A$ summary of the time course of synaptic potentiation in L30 following L29 activation. The amplitude of the monosynaptic IPSP from L30 to L29 was measured $10,20,30$, or $40 \mathrm{sec}$ following direct $\mathrm{L} 30$ activation. These measures, as well as those from recovery tests (1 min following L29 activation), are expressed as difference scores from pretest measures. ${ }^{* *}, p<0.01$ compared to baseline.
A
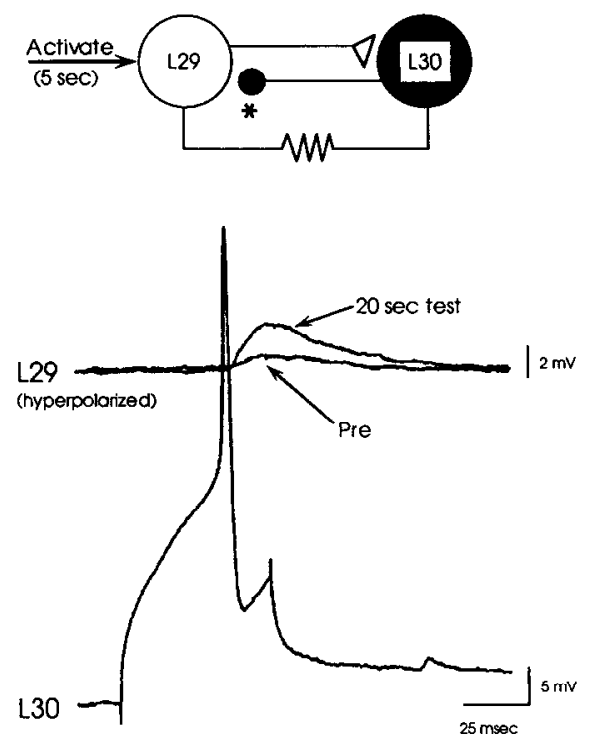

B

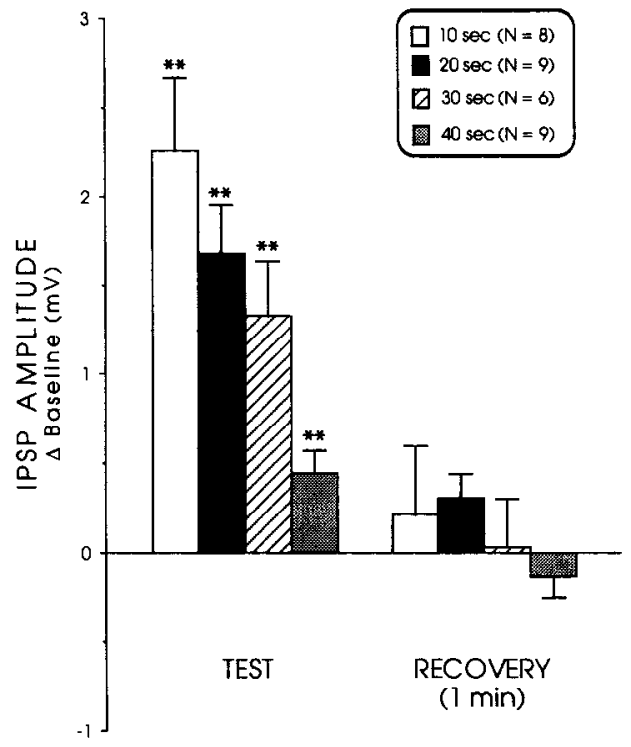

plasticity (for review, see Carew and Sahley, 1986; Byrne, 1987; Hawkins et al,, 1987). This research has mainly centered on the synaptic connection between identified sensory neurons and their follower cells, work that has elucidated cellular correlates that contribute to certain forms of learning (Castellucci and Kandel, 1976; Kandel and Schwartz, 1982; Hawkins et al., 1983; Byrne, 1987). The role of interneurons in the regulation of siphon responses is less well understood. A primary focus has been on their role as modulators of sensory neuron synaptic transmission. This research has identified a number of cells, among them the L29 interneurons examined here, whose activation can either facilitate LE sensory neuron transmission (Hawkins et al., 1981b; Mackey et al., 1989) or inhibit it (Mackey et al., 1987; Small et al., 1992).

Interneurons also have an important mediating role in producing siphon responses through their direct synaptic connections to motor neurons. This has been well documented in the neural analysis of siphon/gill respiratory pumping behavior, in which an identified set of interneurons (collectively named interneuron II) has been shown important for both the initiation and mediation of respiratory pumping (Byrne and Koester, 1978; Byrne, 1983; Koester, 1989). Because interneurons can serve as both premotor cells and modulators, they can provide an important locus for learning-induced modifications of the SWR neural network. For example, Eberly and Pinsker (1984) have demonstrated that under certain conditions, changes in the probability of triggering respiratory pumping (hence activating the interneuron Il network) can significantly contribute to both habituation and sensitization of siphon responses. The locus of this change is likely within the interneuron II network itself (Koester, 1989).

Recent observations demonstrate that interneuronal processes are also important for modifications of the SWR as well. Elcctric shocks applicd to the tail producc a transicnt inhibition of both the reflex (Mackey et al., 1987; Marcus et al., 1988) and complex EPSPs in siphon motor neurons (Wright et al., 1991); this effect is mimicked by the exogenous application of 5-HT (Fitzgerald and Carew, 1991). Following a short-lived inhibition of the LE sensory neuron EPSP induced by tail shock, facilitation of the sensory neuron EPSP is observed (Mackey et al., 1987; Wright et al., 1991; Small et al., 1992), while at the same time the complex EPSP and the reflex still exhibit significant inhibition (Fitzgerald and Carew, 1991; Wright et al., 1991). This dissociation between the polysynaptic and monosynaptic input to motor neurons suggests that interneurons are of major importance in mediating this form of inhibitory plasticity. These data further demonstrate that treatments that are known to induce learning in Aplysia are likely to elicit a number of parallel alterations throughout the SWR neural network. This idea was emphasized by Frost et al. (1988), who provided considerable evidence that a number of physiological modifications in the SWR circuit occur in parallel as a result of pleural-abdominal connective stimulation (discussed below), which is used as a cellular analog of sensitization.

In the present article, we have examined the interneuronal circuit between the excitatory interneuron L29 and the inhibitory interneuron L30, and provide evidence that this circuit is capable of playing an important role in regulating siphon motor neuron excitation through a use-dependent mechanism. First, L29 provides significant excitatory input to the LFS motor neurons. Voltage-clamp inactivation of a single L29 (out of a possible five) significantly reduces the siphon tap-evoked complex EPSPs in these motor neurons. In light of the weak electrical coupling between L29 interneurons (Hawkins et al., 1981a), a possible confound in these experiments is that voltage-clamp inactivation of one L29 interneuron may affect the responses of other L29 interneurons in the SWR circuit, hence overestimating the contributions of individual L29s to evoked motor neuron responses. We addressed this possibility in separate control experiments, in which the tap-evoked responses of other L29 interneurons (two experiments) or L30 interneurons (two experiments) were examined during voltage-clamp inactivation of a single L29 interncuron. In no case was therc a qualitative or quantitative change in the response of the other L29s or L30s during inactivation of the voltage-clamped L29. The experiments examining L30 responses are particularly informative, since the L29 interneurons are strongly electrically coupled to these cells (Hawkins et al., 1981a; see Fig. 6C). Thus, we are 
confident that we are only inactivating the L29 interneuron directly under voltage clamp in these experiments.

Next, activation of L29 produces a net inhibition of siphon tap-evoked input (complex EPSP) to LFS motor neurons. Several lines of evidence show that this inhibitory effect is due to the recruitment and enhancement of inhibitory transmission within the SWR circuit, as opposed to any intrinsic changes within L29 itself. First, an activated L29 need not have a direct synaptic input to a particular LFS motor neuron to induce a reduction in its evoked response. Second, L29 activation results in a reduced tap-evoked response of other, nonactivated L29 interneurons. Third, we provide evidence that the likely mechanism of L29-induced inhibition is an activity-dependent potentiation of inhibitory synaptic transmission from L30 neurons. L29 and L30 are tightly coupled both chemically and electrically so that activation of L 29 invariably generates activity in L30. L30, in turn provides recurrent inhibition onto L29 (Hawkins et al., 1981a). Substituting direct activation of L30 mimics the inhibitory effects seen with L29 activation, reducing the evoked responses of both L29 and LFS motor neurons (LFS neurons receive no direct synaptic input from L30). Furthermore, the L30 IPSP is significantly enhanced as a result of activity, whether produced by direct intracellular activation, or indirectly by driving L29. The potentiation of the L30 IPSP has a time course of decay that directly mirrors the timc coursc of L29-induced inhibition of evoked motor neuron responses. Thus, the mechanism of L29-induced inhibition appears to involve the activation and potentiation of L30 inhibitory transmission. This effectively removes $\mathrm{L} 29$ from the SWR circuit, eliminating a significant source of excitatory input to LFS motor neurons.

Our results differ from those obtained by Hawkins et al. (1981b), who found an increase in the size of motor neuron complex EPSPs as a result of L29 activation. There are several important differences between our experiments that may account for this dissimilarity. First, Hawkins et al. (1981b) monitored responses in an identified gill motor neuron, L7, whereas we examined responses in identified siphon motor neurons. Recently, Hawkins et al. (1990) have shown that gill and siphon responses can be simultaneously modified in different directions, the gill showing enhanced responses at the same time siphon responses are reduced, suggesting some independence of siphon and gill modifications. Interestingly, there appears to be no direct synaptic connection between L29 and L7 (Hawkins et al., 1981a). It will thus be of interest to determine the extent to which modifications of the L29-L30 circuit provide for siphonspecific plasticity. Second, Hawkins et al. (1981b) examined decremented responses; facilitation was expressed as an increase in response above that predicted by a habituation function. Our experiments were performed at an ISI $(5 \mathrm{~min})$ that did not produce decremented responses. Decrementing the reflex may alter the way in which responses are modified; for example, Marcus et al. (1988) demonstrated that nondecremented siphon responses were more susceptible to inhibitory modulation as a result of tail shock. Third, Hawkins et al. (1981b) used electric shocks to the siphon nerve to evoke the response, whereas we used tactile stimuli applied to the siphon itself. It is possible that the electric shocks may result in activation of neurons that are not activated by the peripheral sensory stimuli used here. Relevant to this, it has been shown that tactile stimuli to the siphon can evoke a reflex that does not involve activation of the LE sensory neurons (Cohen et al., 1991). We have also observed in numerous instances that the siphon tap used in this study does not activate the LE sensory neurons (Fischer and Carew, unpublished observations). One possibility, then, is that electrical stimulation of the siphon nerve invokes a contribution of LE sensory neurons (and their follower cells) that is not present in our experiments, perhaps altering the relative contributions of different sets of neurons in the SWR circuit.

Our results address an issue that has been raised in experiments using optical recording techniques to examine the simultaneous activity of multiple neurons in the abdominal ganglion. Using these techniques, Zecevic et al. (1989) demonstrated that tactile stimuli to the siphon can activate as many as 300 neurons, leading these authors to suggest the possibility that the number of neurons evoked by siphon stimulation may be sufficiently large to preclude any determination of the relevance of individual neurons (or neuron classes) to the mediation of behavior. By demonstrating that inhibitory modulation of L29 activity can significantly effect motor neuron responses, our results show that individual neurons do contribute significantly to the control of siphon responses. For example, voltage-clamp inactivation of a single $\mathrm{L} 29$ can reduce the net reflex input to siphon motor neurons by as much as $40 \%$ (and on average produces a significant reduction of $15 \%$ ). Moreover, activation of a single L 30 interneuron results in an average of $24 \%$ reduction in motor neuron responses $20 \mathrm{sec}$ following the activation. In addition to our results, Wright and Carew (1990) have shown that a single abdominal ganglion interneuron, L16, plays an essential role in the behavioral inhibition of siphon responses resulting from tail shock. Specifically, they have demonstrated that L16 is active during tail shock, that direct L16 activation can mimic tail shock-induced inhibition, and that voltage-clamp inactivation of a single L16 during tail shock completely prevents the occurrence of inhibition (Wright and Carew, 1990). Taken together, these results show that single neurons, as well as small subsets of neurons, can have great relevance to the regulation of behavior. While it is likely that other, presently unidentified neurons also contribute significantly to both response production and modification in the SWR (as well as to other behavioral systems receiving siphon input), our results suggest that several identifiable interneurons can provide a focal point in the Aplysia nervous system for a tractable analysis of neural network interactions and behavior.

\section{Functional significance of the L29-L30 circuit: dynamic, use-dependent gain control}

Our results demonstrate a significant correlation between L30 firing frequency and potentiation of the L30 IPSP: higher frequencies of activation result in greater potentiation. Thus, the L30 IPSP is enhanced in an activity-dependent fashion. In addition, we have observed that the L30 IPSP potentiates even at low frequencies of activation; for example, we have obtained significant potentiation at rates as low as $1.8 \mathrm{~Hz}$. We have observed in these and other experiments that this frequency is well below that which is attainable using stimuli applied cutaneously to the siphon or tail (Fischer and Carew, unpublished observations). These observations suggest that L30 can exert a powerful inhibitory influence onto its follower cells that is regulated in an activity-dependent fashion.

In this article we have shown that $\mathrm{L} 30$ can have a significant influence in the SWR circuit through the potentiation of its recurrent inhibitory synapse onto L29. Figure 11 is a summary on how L29-L30 interactions may thus function as a circuit 


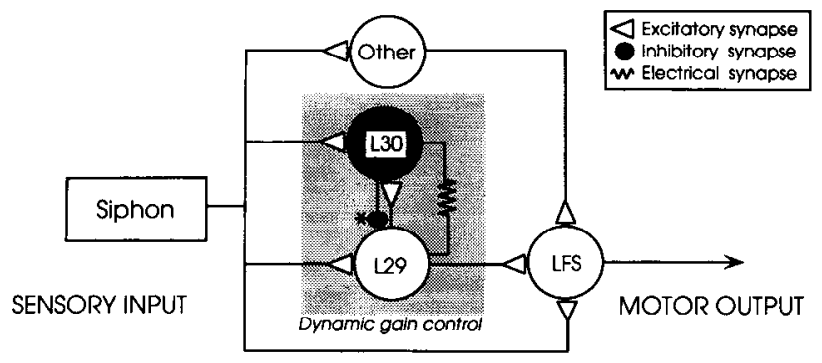

*Activity-dependent facilitotion

Figure 11. The L29-L30 circuit provides dynamic gain control in the SWR circuit. A simplified representation of the neural circuit underlying directional siphon responses (mediated by the LFS motor neurons) is shown to highlight a possible functional role of the L29-L30 circuit (in shaded box). Interactions between these interneurons can provide a usedependent mechanism for regulating excitatory input to LFS motor neurons (dynamic gain control), through the activity-dependent facilitation of the L30 monosynaptic IPSP (asterisk) (see Discussion).

that regulates excitatory input to LFS motor neurons. The activation level of L29 we have used in our experiments (20-30 $\mathrm{Hz}$ for $5 \mathrm{sec}$ ) is well within a physiological range. For example, a moving tactile stimulus across the tail will activate L29 at this frequency or higher for the duration of the stimulus (Fischer and Carew, unpublished observations), and tail input is known to produce inhibition of the SWR (Mackey et al., 1987; Marcus et al., 1988; Wright et al., 1991). How, then, does L29 affect L30? In essence, the more L29 is active, the more L30 fires, increasing the efficacy of its IPSP onto L29 (and presumably other follower cells). This has the effect of removing L29 from the SWR circuit. Since L29 is a major excitatory input to the LFS-type motor neurons, L29-L30 interactions alone can function as a circuit that provides a dynamic gain control of excitatory input to these motor neurons.

Consistent with the idea that inhibitory modulation of reflex activity can be achieved through $\mathrm{L} 30$, we have recently obtained evidence that cutaneous stimulation of the tail produces similar inhibitory effects in the SWR circuit as those reported here, transiently inhibiting siphon tap-evoked responses both in LFS motor neurons and in a subtype of L29 interneurons that do not discharge to the tail stimuli (similar to the the L29 $\mathrm{A}$ cells reported by Hawkins and Schacher, 1989). Further, this inhibition has a time course similar to the potentiation of the I. 30 IPSP that we observe (about $40 \mathrm{sec}$ ). Finally, we have obtained preliminary evidence that these cutaneous tail stimuli both strongly activate L30 and potentiate the L30 IPSP; we do not yet know the extent to which the excitatory drive on L30 under these conditions is mediated through L29. We are now carrying out experiments to test directly the involvement of L 30 in this form of reflex inhibition by voltage-clamp inactivation of L30 during application of tail stimuli.

In addition to the recurrent (feedback) inhibitory effects discussed thus far, L30 may also have significant feedforward inhibitory effects on other neural circuits. L30 has identified input to a number of neurons in the abdominal ganglia, some of which have been identified (Hawkins et al., $1981 \mathrm{a}$; Frost, 1987). We have also obscrved that L30 has synaptic input to many other neurons that have yet to be uniquely identified. Moreover, we have found in several instances that the L30 IPSP to these other neurons also shows activity-dependent potentiation (Fischer and
Carew, unpublished observations), suggesting that L30 can have widespread inhibitory effects on a number of response and regulatory systems. The observed plasticity of the L30 synapse makes this neuron an intriguing subject for studies examining the role of inhibitory processing on the functioning of neural circuits.

\section{Possible behavioral significance of the L29-L30 circuit}

Recurrent inhibitory circuits like that formed by L29 and L30 are a common architectural feature of nervous systems, and have been demonstrated to be important for the modulation of the output of several diverse neural circuits. One well-studied example of recurrent inhibition is the circuit between Renshaw cells and $\alpha$-motor neurons in the spinal cord. Renshaw cells provide a tonic inhibitory influence on motor neurons that is regulated in part by the motor neuron itself, as well as through a number of extrinsic sources (Pompeiano, 1984). Moreover, extrinsic inputs can exert a significant control over the gain of spinal cord reflexes through the modification of recurrent inhibition. For example, electrical stimulation of the locus coeruleus can increase the response gain of certain spinal reflexes through decreasing Renshaw cell activity (Fung et al., 1988). Similar modifications of recurrent inhibition have been shown important for processing in a number of other neural circuits, such as in the hippocampus (Miles, 1991). Since recurrent inhibitory circuits can provide a powerful mechanism for the modulation and control of neural output, a question of general significance is how (or whether) recurrent inhibition contributes to neural processes underlying adaptive alterations of circuit functioning such as occurs during learning. In this regard, the L29-L30 circuit is particularly intriguing because it is a recurrent inhibitory circuit with a built-in mechanism for synaptic plasticity, activity-dependent potentiation of the L 30 inhibitory synapse.

The behavioral significance of the L29-L30 circuit is as yet unknown. However, the dynamics of L29-L30 interactions that we have observed provide testable predictions for the involvement of this circuit in different forms of behavioral plasticity. For example, since the L30 IPSP potentiates at low rates of activation, one prediction might be that this circuit may have a direct role in habituation, a form of learning exhibited by the SWR (see, e.g., Carew et al., 1972). Repeated activation of the SWR (and consequently repeated L29-L30 activation) may be sufficient to potentiate the L30 IPSP, moving the balance of the circuit towards inhibition and thus decreasing the net excitatory input to motor neurons. Hence, one component of habituation in the SWR may involve a buildup of inhibition in the L29L30 circuit.

Additional modifications of the L29-L30 circuit, potentially from extrinsic sources, could also play an important role in the response facilitation seen with sensitization. This could be accomplished through the removal of the inhibitory influence of L 30, in essence enhancing excitatory transmission in the SWR circuit. In this way, enhancement of siphon responses would be accomplished through a disinhibition mechanism similar to that observed in the vertebrate spinal cord (Fung et al., 1988). Evidence for this type of disinhibitory mechanism has been provided by Frost et al. (1988), who demonstrated parallel modifications in the L29-L30-LFS motor ncuron circuit using pleuralabdominal connective stimulation, an analog of sensitization. They found that connective shock induces presynaptic inhibition of the L30 synapse, effectively reducing the size of the L30 
synapse, effectively reducing the size of the L30 IPSP. This was coupled with a concomitant potentiation of the L29 EPSP to LFS motor neurons, and an increase in LFS excitability, having the net effect of increasing the efficiency of L29's excitatory input to the LFS motor neurons (Frost et al., 1988). These circuit modifications suggest important candidate mechanisms contributing to sensitization of the SWR. Further, since the LFS motor neurons have been identified as those which mediate directional siphon responses (Walters and Erickson, 1986; Hickie and Walters, 1990), this circuit can play an important role in the regulation and modulation of this behavior, such as that demonstrated in several studies of both associative and nonassociative modifications of directional siphon responses (Erickson and Walters, 1988; Hawkins et al., 1989; Walters, 1989).

Finally, the facilitatory and inhibitory interactions in the SWR offer an excellent opportunity for a computational analysis of information processing in a restricted ncural circuit (Blazis et al., 1991, 1992, in press). The dynamic interactions within the L29-L30 circuit itself form a restricted computational network that is capable of effecting substantial alterations of information processing in the SWR circuit, as well as serving as a potentially important locus for different forms of external modulation. Thus, a computational analysis, coupled with behavioral and cellular studies, may provide important insights into different models of information processing that contribute to different forms of learning and memory.

\section{References}

Abrams TW, Castellucci VF, Camardo JS, Kandel ER, Lloyd PE (1984) Two endogenous neuropeptides modulate the gill and siphon withdrawal reflex in Aplysia by presynaptic facilitation involving c-AMP dependent closure of a serotonin-sensitive potassium channel. Proc Natl Acad Sci USA 81:7956-7960.

Blazis DEJ, Berkowicz DA, Kairiss EW, Carew TJ (1991) A network model of inhibitory information processing in the siphon withdrawal reflex of Aplysia. Soc Neurosci Abstr 17:1302.

Blazis DEJ, Fischer TM, Carew TJ (1992) A neural network model of use-dependent gain control in the siphon withdrawal reflex of Aplysia. Soc Neurosci Abstr 18:713.

Blazis DEJ, Fischer TM, Carew TJ (in press) A neural network model of inhibitory information processing in Aplysia. Neural Comput, in press.

Brunelli M, Castellucci V, Kandel ER (1976) Synaptic facilitation and behavioral sensitization in Aplysia: possible role of serotonin and cyclic AMP. Science 194:1178-1180.

Byrne JH (1983) Identification and initial characterization of a cluster of command and pattern-generating neurons underlying respiratory pumping in Aplysia californica. J Neurophysiol 49:491-508.

Byrne JH (1987) Cellular analysis of associative conditioning. Physiol Rev 67:329-439.

Byrne J, Koester J (1978) Respiratory pumping: neuronal control of a centrally commanded behavior in Aplysia. Brain Res 143:87-105.

Carew TJ, Sahley CL (1986) Invertebrate learning and memory: from behavior to molecules. Annu Rev Neurosci 9:435-487.

Carew TJ, Pinsker HM, Kandel ER (1972) Long-term habituation of a defensive withdrawal reflex in Aplysia. Science 175:451-454.

Castellucci VF, Kandel ER (1976) Presynaptic facilitation as a mechanism for behavioral sensitization in Aplysia. Science 194:1176-1178.

Cohen TE, Henzi V, Kandel ER, Hawkins RD (1991) Further behavioral and cellular studies of dishabituation and sensitization in Aplysia. Soc Neurosci Abstr 17:1302.

Eberly LB, Pinsker HM (1984) Neuroethological studies of reflex plasticity in intact Aplysia. Behav Neurosci 98:609-630.

Erickson MT, Walters ET (1988) Differential expression of psuedoconditioning and sensitization by siphon responses in Aplysia: novel response selection after training. J Neurosci 8:3000-3010.

Fischer TM, Carew TJ (1991) Activation of the facilitatory interneu- ron L29 produces inhibition of reflex input to siphon motor neurons in Aplysia. Soc Neurosci Abstr 17:1302.

Fitzgerald K, Carew TJ (1991) Serotonin mimics tail shock in producing transient inhibition in the siphon withdrawal reflex of Aplysia. J Neurosci 11:2510-2518.

Fitzgerald K, Wright WG, Marcus EA, Carew TJ (1990) Multiple forms of nonassociative plasticity in Aplysia: a behavioural, cellular, and pharmacological analysis. Philos Trans R Soc Lond [Biol] 329: $171-178$.

Frost WN (1987) Mechanisms contributing to short- and long-term sensitization in Aplysia. PhD thesis, Columbia University.

Frost WN, Clark GA, Kandel ER (1988) Parallel processing of shortterm memory for sensitization in Aplysia. J Neurobiol 19:297-334.

Fung SJ, Pompeiano O, Barnes CD (1988) Coerulospinal influence on recurrent inhibition of spinal motonuclei innervating antagonistic hindleg muscles of the cat. Pfluegers Arch 412:346-353.

Getting PA (1989) Emerging principles governing the operation of neural networks. Annu Rev Neurosci 12:185-204.

Harris-Warrick RM, Marder E (1991) Modulation of neural networks for behavior. Annu Rev Neurosci 14:39-57.

Hawkins RD, Schacher S (1989) Identified facilitator neurons L29 and L28 are excited by cutaneous stimuli used in dishabituation, sensitization, and classical conditioning of Aplysia. J Neurosci 9:42364245.

Hawkins RD, Castellucci VF, Kandel ER (1981a) Interneurons involved in mediation and modulation of gill-withdrawal reflex in Aplysia. I. Identification and characterization. J Neurophysiol 45:304 314.

Hawkins RD, Castellucci VF, Kandel ER (1981b) Interneurons involved in mediation and modulation of gill-withdrawal reflex in $A p l y$ sia. II. Identified neurons produce heterosynaptic facilitation contributing to behavioral sensitization. J Neurophysiol 45:315-326.

Hawkins RD, Abrams TW, Carew TJ, Kandel ER (1983) A cellular mechanism of classical conditioning in Aplysia: activity-dependent amplification of presynaptic facilitation. Science 219:400-405.

Hawkins RD, Clark GA, Kandel ER (1987) Cell biological studies of learning in simple vertebrate and invertebrate systems. In: Handbook of physiology, Sec I, Higher functions of the nervous system (Plum F, ed), pp 25-83. Bethesda, MD: American Physiological Society.

Hawkins RD, Lalevic N, Clark GA, Kandel ER (1989) Classical conditioning of the Aplysia siphon-withdrawal reflex exhibits response specificity. Proc Natl Acad Sci USA 86:7620-7624.

Hawkins RD, Cohen TE, Henzi VA, Kandel ER (1990) Parallel dishabituation and sensitization with no inhibition of gill-withdrawal reflex in Aplysia. Soc Neurosci Abstr 16:19.

Hickie C, Walters ET (1990) Identified central motor neurons are necessary for directional siphon responses in Aplysia. Soc Neurosci Abstr 16:19.

Kandel ER (1979) Behavioral biology of Aplysia. San Francisco: Freeman.

Kandel ER, Schwartz JH (1982) Molecular biology of an elementary form of learning: modulation of transmitter release by cyclic AMP. Science 218:433-443.

Kesner RP (1984) The neurobiology of memory: implicit and explicit assumptions. In: Neurobiology of learning and memory (Lynch $G$, McGaugh JL, Weinberger NM, eds), pp 235-243. New York: Guilford.

Koester J (1989) Chemically and electrically coupled interneurons mediate respiratory pumping in Aplysia. J Neurophysiol 62:11131126.

Kretz R, Shapiro E, Connor J, Kandel ER (1984) Posttetanic potentiation, presynaptic inhibition, and the modulation of free $\mathrm{Ca}^{2+}$ level in presynaptic terminals. Exp Brain Res [Suppl] 9:240-283.

Levine DS, Leven SJ (1991) Inhibition in the nervous system: models of its roles in choice and context determination. Neurochem Res 16: 381-395.

Mackey SL, Glanzman DL, Small SA, Dyke AM, Kandel ER, Hawkins RD (1987) Aversive stimuli produce inhibition as well as sensitization of the siphon withdrawal reflex of Aplysia: a possible behavioral role for presynaptic inhibition mediated by the peptide FMRFamide. Proc Natl Acad Sci USA 84:8730-8734.

Mackey SL, Kandel ER, Hawkins RD (1989) Identified serotonergic interneurons LCB 1 and RCB1 in the cerebral ganglia of Aplysia produce presynaptic facilitation of siphon sensory neurons. J Neurosci 9:4227-4235.

Marcus EA, Nolen TG, Rankin CH, Carew TJ (1988) Behavioral 
dissociation of dishabituation, sensitization, and inhibition of $A p l y$ sia. Science 241:210-213.

Miles R (1991) Tetanic stimuli induce a short-term enhancement of recurrent inhibition in the CA3 region of guinea-pig hippocampus in vitro. J Physiol (Lond) 443:669-682.

Pompeiano O (1984) Recurrent inhibition. In: Handbook of the spinal cord (Davidoff N, ed), pp 461-557. New York: Decker.

Small SA, Cohen TE, Kandel ER, Hawkins RD (1992) Identified FMRFamide-immunoreactive neuron LPL16 in the left pleural ganglion of Aplysia produces presynaptic inhibition of siphon sensory neurons. J Neurosci 12:1616-1627.

Thompson RF (1989) Neural circuit for classical conditioning of the eyelid closure response. In: Neural models of plasticity (Byrne $\mathrm{JH}$, Berry WO, eds), pp 160-177. San Diego: Academic.

Walters ET (1989) Transformation of siphon responses during conditioning of Aplysia suggests a model of primitive stimulus-response association. Proc Natl Acad Sci USA 86:7616-7619.
Walters ET, Erickson MT (1986) Directional control and the functional organization of defensive responses in Aplysia. J Comp Physiol [A] 159:339-351.

Weinberger NM, Ashe JH, Metherate R, McKenna TM, Diamond DM, Bakin J (1990) Retuning auditory cortex by learning: a preliminary model of receptive field plasticity. Concepts Neurosci 1:91-132.

Wright WG, Carew TJ (1990) Contribution of interneurons to tail shock induced inhibition of the siphon withdrawal reflex of Aplysia. Soc Neurosci Abstr 16:20.

Wright WG, Marcus EA, Carew TJ (1991) A cellular analysis of inhibition in the siphon withdrawal reflex of Aplysia. J Neurosci 11: 2498-2509.

Zecevic D, Wu J-Y, Cohen LB, London JA, Hoepp H-P, Falk C-X (1989) Hundreds of neurons in the Aplysia abdominal ganglion are active during the gill withdrawal reflex. J Neurosci 9:3681-3689. 